\title{
3'-End-Dependent Formation of U6 Small Nuclear Ribonucleoprotein Particles in Xenopus laevis Oocyte Nuclei
}

\author{
MICHAEL P. TERNS, * ELSEBET LUND, AND JAMES E. DAHLBERG \\ Department of Biomolecular Chemistry, University of Wisconsin-Madison, Madison, Wisconsin 53706
}

Received 28 January 1992/Accepted 24 April 1992

\begin{abstract}
We have identified and characterized a U6 small nuclear (sn) ribonucleoprotein particle (RNP) present in the nuclei of Xenopus laevis oocytes. The structure of this U6 snRNP was investigated by native gel shift analysis and a combination of RNA-protein UV cross-linking, RNase T1 fingerprinting, and immunoprecipitation assays. These analyses demonstrate that certain forms of U6 snRNA associate with the 50-kDa nuclear antigen La both in vivo and in vitro. The La protein binds the stretch of uridylates at the $3^{\prime}$ hydroxyl end of newly synthesized U6 snRNA. La does not bind to mature U6 snRNAs that have $2^{\prime}, 3^{\prime}$-cyclic phosphate $(>$ p) groups at their $3^{\prime}$ ends (E. Lund and J. E. Dahlberg, Science 255:327-330, 1992) or to U6 snRNAs in anti-Smprecipitable U4/U6 snRNPs. We propose that $3^{\prime}$-end modification, including posttranscriptional UMP addition, modulates the binding of La protein to U6 snRNA which, in turn, may affect the function of this RNA.
\end{abstract}

Removal of introns from precursor mRNA (splicing) requires the participation of the major small nuclear ribonucleoprotein particles (RNPs), which consist of U1, U2, U4, U5, and U6 snRNAs and their associated proteins (reviewed in references 27 and 45). U6 snRNA differs from U1 to U5 snRNAs in several ways. It is synthesized by RNA polymerase III rather than RNA polymerase II, it contains a $\gamma$-methyltriphosphate $5^{\prime}$ end instead of a trimethylated guanosine 5 ' cap structure, and it lacks an Sm-binding site (reviewed in references $11,19,25$, and 39). U6 RNA is also unique in that uridylate (UMP) residues are both added to and removed from its $3^{\prime}$ end posttranscriptionally $(22,30,37)$ and mature forms of this snRNA contain a $2^{\prime}, 3^{\prime}$-cyclic phosphate terminal group (30). Furthermore, maturation and functioning of U6 RNA appear to be accomplished solely in the nucleus $(32,47)$ whereas generation of $U 1$ to U5 snRNPs requires transit through the cytoplasm (reviewed in reference 35).

U6 RNA has been detected in U6 $\operatorname{snRNP}(3,10,17,20)$, U4/U6 bi-snRNP $(4,21)$, and U4/U5/U6 tri-snRNP complexes $(2,3,23)$. However, since the levels of U6 RNA are 2- to 20-fold higher than those of U4 snRNA in organisms as diverse as Saccharomyces cerevisiae (10), frogs (20), and humans (3), only a fraction of U6 RNA is present in these biand tri-snRNP complexes.

Relatively little is known about proteins that bind specifically to U6 RNA. Consistent with the notion that U6 RNA is a product of RNA polymerase III transcription, a minor fraction of mammalian U6 RNA has previously been shown to associate with the La antigen $(37,41)$. The La antigen, an evolutionarily well-conserved $\sim 50-\mathrm{kDa}$ nuclear protein, associates with a number of cellular and viral RNAs synthesized by RNA polymerase III $(8,15,40)$ primarily at their 3 '-terminal uridylate tracts $(8,33,38,44)$. A 50 - to $55-\mathrm{kDa}$ protein capable of binding the $5^{\prime}$-terminal domain of U6 RNA was recently found in extracts of HeLa cells and trypanosomes, but further characterization of this protein was not reported (17). Although U6 RNA was observed to bind to a $50-\mathrm{kDa}$ protein in Xenopus laevis oocytes, the researchers claimed that the protein was not precipitable by anti-La antibodies (20). However, analysis of the interaction

\footnotetext{
${ }^{*}$ Corresponding author.
}

between La and RNAs is complicated by the use of various preparations of anti-La antibodies that differ considerably in the ability to recognize the La proteins of divergent organisms (9) or the La protein in La-RNPs.

In view of the unique character of U6 RNA and its importance in splicing, we investigated the RNP structure of nuclear U6 RNA by using the $X$. laevis oocyte system. U6 snRNPs from three sources were analyzed: (i) those naturally present in oocyte nuclei (endogenous), (ii) those assembled in isolated oocyte nuclei following transcription of injected U6 genes (in vivo), and (iii) those resulting from incubation of U6 RNA synthesized in vitro and proteins of oocyte nuclear extracts (reconstituted). Our results demonstrate that U6 RNA associates specifically with the La protein both in vivo and in vitro. The principal site of interaction between the La protein of $X$. laevis and wild-type U6 RNA is at the oligouridylate-containing $3^{\prime}$ hydoxyl end. La associates with newly synthesized U6 RNAs and endogenous U6 RNAs containing 3' $\mathrm{OH}$ ends but not with mature U6 RNAs which carry a $2^{\prime}, 3^{\prime}$-cyclic phosphate $(>p)$ at their $3^{\prime}$ ends. Furthermore, incorporation of U6 RNA into the U4/U6 snRNP is accompanied by apparent loss of $\mathrm{La}$ binding.

\section{MATERIALS AND METHODS}

Preparation of in vivo U6 transcripts, U4/U6 snRNPs, and oocyte germinal vesicle (GV) extracts. DNA templates used in this study were the wild-type $X$. tropicalis U6 gene (24), the chicken U4 gene (47), and a U6 deletion mutant ( $\Delta$ ss, lacking nucleotides 20 to 25 [20]). U6 snRNPs were either those naturally present in stage VI oocyte nuclei (GVs) or those assembled in intact GVs (referred to as in vivo particles). In vivo U6 snRNPs were synthesized by microinjection of cloned U6 genes in $X$. laevis oocytes $(29,32)$. The preinjected GVs were then isolated from the cytoplasm by manual dissection under mineral oil $(29,31)$, and transcription was allowed to proceed, usually for 1 to $2 \mathrm{~h}$ in the presence of $\left[\alpha^{-32} \mathrm{P}\right] \mathrm{GTP}(0.5 \mu \mathrm{Ci}$ per GV) and UTP $(1.0 \mu \mathrm{Ci}$ per $\mathrm{GV})$ under oil at $19^{\circ} \mathrm{C}$. GV extracts were prepared in extract buffer (EB) (40 mM HEPES [ $N$-2-hydroxyethylpiperazine$N^{\prime}$-2-ethanesulfonic acid], $\mathrm{pH} 7.9$, with $\mathrm{KOH}, 100 \mathrm{mM}$ potassium acetate $8 \%$ glycerol, $5 \mathrm{mM} \mathrm{MgSO}_{4}, 2$ mM EGTA 
[ethylene glycol-bis( $\beta$-aminoethyl ether)- $N, N, N^{\prime}, N^{\prime}$-tetra acetic acid], $0.2 \mathrm{mM}$ EDTA, $1 \mathrm{mM}$ dithiothreitol, $0.5 \%$ aprotinin, $2 \mu \mathrm{g}$ each of leupeptin and pepstatin A per $\mathrm{ml}$, and $0.1 \mathrm{U}$ of RNAsin per $\mu \mathrm{l}$ ) at a concentration of 1 to $4 \mu \mathrm{l}$ of EB buffer per GV by repeatedly pipetting the mixture on ice. Following a 15-s centrifugation step to clarify the homogenate, the extract containing the U6 snRNP complexes was quickly frozen in a semisolid slush of $-70^{\circ} \mathrm{C}$-chilled $80 \%$ isopropanol and stored in small aliquots at $-70^{\circ} \mathrm{C}$.

To prepare labeled U4/U6 snRNPs in vivo, oocyte nuclei were injected with $\mathrm{U} 4$ and $\mathrm{U} 6$ genes $(5.0$ and $0.1 \mathrm{ng}$, respectively, per oocyte) plus $\left[\alpha^{-3} \mathrm{P}\right] \mathrm{GTP}$ and $\left[{ }^{32} \mathrm{P}\right] \mathrm{UTP}$ and incubated for $16 \mathrm{~h}$ at $19^{\circ} \mathrm{C}$ to assemble U4/U6 snRNPs. GV extracts were then prepared as described above and analyzed.

${ }^{35} \mathrm{~S}$-labeled GV proteins were obtained by incubating stage $\mathrm{VI}$ oocytes for at least $24 \mathrm{~h}$ in the presence of $1.0 \mathrm{mCi}$ of $\left[{ }^{35} \mathrm{~S}\right]$ methionine (NEN, Dupont) per ml of MBS-H medium (18), and GV extracts were prepared from the labeled oocytes as described above and analyzed as described below.

Preparation of in vitro U6 transcripts. The template used for production of synthetic U6 snRNA was generated by polymerase chain reaction amplification. The $5^{\prime}$ primer $\left(5^{\prime}-\right.$ TAA TAC GAC TCA CTA TAG GGT GCT TGC TTC GGC AGC ACA TAT AC-3') contained the T7 bacteriophage promoter and sequences complementary to the $5^{\prime}$ end of the U6 gene. The $3^{\prime}$ primer (5'-AAA AAT ATG GAA CGC TTC AC $-3^{\prime}$ ) is complementary to the $3^{\prime}$ end of the U6 gene. Wild-type U6 plasmid DNA from $X$. tropicalis (24) was the target sequence, and the polymerase chain reaction was cycled 35 times under the following conditions: $95^{\circ} \mathrm{C}$ for $45 \mathrm{~s}$, $50^{\circ} \mathrm{C}$ for $45 \mathrm{~s}$, and $72^{\circ} \mathrm{C}$ for $75 \mathrm{~s}$. The 109-nucleotide transcripts generated from this template (called T7U6 RNA) have the same sequence as the Xenopus U6 RNA except for two additional $\mathrm{G}$ residues at the $5^{\prime}$ end.

In vitro transcription of $\mathrm{T} 7$ or SP6 templates was performed essentially as previously described (34), by using 50 to $100 \mathrm{ng}$ of a polymerase chain reaction DNA fragment or 1 $\mu \mathrm{g}$ of a linearized plasmid DNA template; ATP, CTP, and GTP each at $0.5 \mathrm{mM}, 0.05 \mathrm{mM}$ UTP; and $30 \mu \mathrm{Ci}$ of $\left[\alpha-{ }^{32}\right.$ P]UTP (NEN, Dupont) in a $20-\mu$ l reaction volume. This same procedure was used to generate unlabeled competitor RNA, except that each nucleoside triphosphate was included at $0.5 \mathrm{mM}$ in the reaction mixture and the reaction volumes were scaled up to 50 or $100 \mu \mathrm{l}$. A $3^{\prime}$-truncated form of U6 RNA was generated by T7 transcription of polymerase chain reaction template DNA restricted by HaeIII. The pGEM-2 vector (Promega) was digested with $P v u I I$ to serve as the template for a control RNA (102 nucleotides long) with sequences unrelated to those of U6 RNA. The in vitro transcripts were gel purified; ${ }^{32} \mathrm{P}$-labeled transcripts were detected in the gels by autoradiography, while unlabeled competitor RNAs were visualized by UV shadowing and subsequently quantified by $A_{260}$ readings. Transcripts were eluted from the gel slices by incubation at room temperature for 10 to $14 \mathrm{~h}$ with $0.5 \mathrm{ml}$ of gel elution buffer $(0.5 \mathrm{M}$ ammonium acetate, $0.1 \%$ sodium dodecyl sulfate [SDS], 0.5 $\mathrm{mM}$ EDTA), purified by phenol extraction and ethanol precipitation, and stored at $-20^{\circ} \mathrm{C}$ in $\mathrm{H}_{2} \mathrm{O}$.

Analysis of RNA transcripts. Purified RNAs were fractionated by electrophoresis for 3 to $4 \mathrm{~h}$ at $1,500 \mathrm{~V}$ by using $8 \%$ (29:1) polyacrylamide gels ( $40 \mathrm{~cm}$ long and $0.4 \mathrm{~mm}$ thick) containing $7 \mathrm{M}$ urea and $0.5 \times$ TBE buffer $(45 \mathrm{mM}$ Trisborate [pH 8.3], 1.15 mM EDTA).

Generation of U6 RNA containing 3' phosphate groups was accomplished by incubation of purified RNA in $100 \mu \mathrm{l}$ of Whitfield's reagent $\left(25 \mathrm{mM} \mathrm{NaIO}_{4}, 1 \mathrm{M}\right.$ lysine, $\left.\mathrm{pH} 8.5\right)$ for 2 $h$ at $45^{\circ} \mathrm{C}(30,44)$. This treatment (oxidation- $\beta$ elimination) also results in shortening of the input RNA by 1 nucleotide.

RNase T1 digestion and two-dimensional fingerprinting were done as previously described $(1,28)$. Briefly, RNase T1 oligonucleotides were separated in the first dimension by high-voltage electrophoresis in urea-pH 3.5 buffer on cellulose acetate strips and in the second dimension by homochromotography on polyethylenimine thin-layer plates. Computer analysis of RNA secondary structure and folding was carried out by using University of Wisconsin Genetics Computer Group RNA secondary-structure programs.

U6 snRNP reconstitution system. Typically, reconstituted U6 snRNPs were assembled in a $10-\mu$ l reaction volume by incubating ${ }^{32} \mathrm{P}$-labeled T7U6 RNA transcripts $(\sim 5,000 \mathrm{cpm}$ or 0.1 to $0.5 \mathrm{ng})$ with $\mathrm{GV}$ extract $(0.25$ to $1.0 \mathrm{GV})$ in the presence of $\mathrm{EB}$ buffer at $30^{\circ} \mathrm{C}$ for $20 \mathrm{~min}$. Addition of exogenous ATP had no apparent effect on RNP formation. RNA-protein complexes were analyzed by native gel electrophoresis by using a discontinuous native gel system $(10 \%$ separating gel) as previously described (7). Samples were mixed with $2.5 \mu \mathrm{l}$ of loading dye $(50 \%$ glycerol, $2.5 \mathrm{mM}$ EDTA, $0.1 \%$ bromphenol blue, xylene cyanol) on ice and electrophoresed at $400 \mathrm{~V}$ at $4^{\circ} \mathrm{C}$ for approximately $4 \mathrm{~h}$. The gels were fixed in $25 \%$ isopropanol and $10 \%$ glacial acetic acid for at least $30 \mathrm{~min}$, and dried under vacuum prior to autoradiography.

UV cross-linking. RNA-protein cross-linking was induced by irradiation of the extract samples with UV light at $254 \mathrm{~nm}$ for $10 \mathrm{~min}$ essentially as previously described (46). For RNase treatment, samples were incubated at $37^{\circ} \mathrm{C}$ for $30 \mathrm{~min}$ with RNase A $(1 \mu \mathrm{g} / \mathrm{ml})$ and RNase T1 $(2.5 \mathrm{U} / \mu \mathrm{l})$. UVirradiated products were heated at $90^{\circ} \mathrm{C}$ for $5 \mathrm{~min}$ in the presence of an equal volume of SDS-gel loading buffer $(0.125$ M Tris- $\mathrm{HCl}$ [pH 6.8], $1 \%$ SDS, $5 \% \beta$-mercaptoethanol, $10 \%$ glycerol, $0.1 \%$ bromphenol blue dye) and analyzed by electrophoresis on discontinuous polyacrylamide gels containing SDS as previously described (13). Cross-linked products were detected by autoradiography of fixed and dried gels.

Mapping of the site of U6 RNA that the La protein cross-links to was accomplished by fractionating UV-irradiated U6 La RNPs (assembled in 50- or 100- $\mu$ l reconstitution reactions) on protein gels. The cross-linked RNP and free RNA were identified by autoradiography at $4^{\circ} \mathrm{C}$, isolated, and eluted from crushed gel slices by rotation for at least 24 $\mathrm{h}$ at $37^{\circ} \mathrm{C}$ in the presence of $5 \mathrm{ml}$ of proteinase $\mathrm{K}$ buffer $(50$ $\mathrm{mM}$ Tris- $\mathrm{HCl}$ [pH 7.6], $10 \mathrm{mM}$ EDTA, 1\% SDS, $0.8 \mathrm{mg}$ of proteinase $\mathrm{K}$ per $\mathrm{ml}$ ). The RNA was purified from the gel bits by low-speed centrifugation and passage through a $0.45-\mu \mathrm{m}$ pore-size filter (Swinnex HA; Millipore), followed by phenol extraction and ethanol precipitation. RNase T1 fingerprinting was performed as described above.

Immunoprecipitation. Antibodies were coupled to preswollen protein A-Sepharose CL-4B beads (Sigma) by incubation in $0.5 \mathrm{ml}$ of $\mathrm{Ipp}_{500}$ buffer $(10 \mathrm{mM}$ Tris-HCl [pH 8.0], $0.1 \%$ Nonidet $\mathrm{P}-40,500 \mathrm{mM} \mathrm{NaCl}, 0.1 \%$ sodium azide) at $4^{\circ} \mathrm{C}$ for 2 to $12 \mathrm{~h}$ with end-over-end rotation. Following three 1.0 -ml washes with Ipp $_{150}$ buffer $(150 \mathrm{mM} \mathrm{NaCl}), \mathrm{GV}$ extracts or cross-linked proteins were added to the beads and brought to $0.25 \mathrm{ml}$ with $\mathrm{Ipp}_{150}$ buffer containing $0.1 \mathrm{U}$ of RNasin per $\mathrm{ml}$ and $2 \mathrm{mM}$ dithiothreitol. After precipitation for $2 \mathrm{~h}$ at $4^{\circ} \mathrm{C}$ with rotation, supernatants were collected for analysis and the beads were washed four times with $1.0 \mathrm{ml}$ of ice-cold Ipp ${ }_{150}$ buffer. Generally, RNAs were released from the beads by incubation at $37^{\circ} \mathrm{C}$ for $30 \mathrm{~min}$ in $200 \mu \mathrm{l}$ of 
proteinase $\mathbf{K}$ buffer. RNAs from both supernatants and precipitates were isolated by phenol extraction and ethanol precipitation and analyzed by denaturing polyacrylamide gel electrophoresis followed by autoradiography. Precipitated proteins or cross-linked RNPs were released from the beads by heating at $90^{\circ} \mathrm{C}$ in the presence $35 \mu \mathrm{l}$ of SDS-gel loading buffer and analyzed on SDS-containing polyacrylamide gels. Gels containing $\left[{ }^{35}\right.$ S $]$ methionine-labeled proteins were treated with fluorographic solution in accordance with the manufacturer's instructions (Amplify; Amersham).

Immunodepletion of GV extract was carried out by coupling a 25- $\mu$ l packed volume of swelled protein A-Sepharose beads with $12.5 \mu \mathrm{l}$ of anti-La serum (and $12.5 \mu \mathrm{l}$ of normal human serum for control experiments) for $12 \mathrm{~h}$ at $4^{\circ} \mathrm{C}$ with rocking. The antibody-coupled beads were then washed four times with $1 \mathrm{ml}$ of Ipp $\mathrm{p}_{150}$, and the excess liquid was removed from the beads after the final wash. GV extracts $(12.5 \mathrm{GV}$ equivalents) were then added to beads and incubated on ice for $2 \mathrm{~h}$ with brief but frequent stirring of the mixture with a pipette tip. The immune complexes were removed from the extract by centrifugation, and the supernatant was used as the source of depleted extract.

Antibodies used in these experiments include a monoclonal (Y12) anti-Sm antibody (26), kindly provided by J. A. Steitz, and anti-Prp24 serum (42), from K. Shannon and C. Guthrie. The anti-La sera were generously supplied by $\mathrm{R}$. Reddy (sera 21, 22, 23, and 84), E. Chan and E. Tan (serum Ze; Centers for Disease Control human anti-SS-B/La reference serum), J. A. Steitz (serum Le), and D. Kenan and J. Keene (sera A-114, A-306, B-103, B-113, B-506, MJ, and GO). Although the reactivities of these sera varied widely, a good correlation usually was observed between the abilities of the various anti-La sera to precipitate both the Xenopus La protein and the La-U6 snRNP. However, the anti-La serum $(\mathrm{Ze})$ precipitated the La protein very efficiently but failed to precipitate the La-bound U6 RNA. Anti-La 22 was the main serum used in these studies.

Northern (RNA) blot analysis. Total and immunoprecipitated RNAs from the equivalent of four GVs were fractionated in $7 \mathrm{M}$ urea-8\% polyacrylamide gels as described above and transferred electrophoretically to nylon membranes (GeneScreen Plus; NEN Dupont). The blots were hybridized with antisense U1, U4, and U6 snRNA probes which were labeled with $\left[{ }^{32} \mathrm{P}\right] \mathrm{UTP}$ during transcription of the corresponding template DNAs (28) by SP6 or T7 RNA polymerase as described above.

\section{RESULTS}

Identification of a nuclear U6 snRNP. U6 snRNA synthesized from injected genes associates with proteins in vivo as shown by native gel electrophoresis of U6 RNAs present in nuclear extracts of $X$. laevis oocytes (Fig. 1, compare lanes 1 and 2; data not shown). The nuclear extract was prepared from isolated oocyte nuclei (GVs) that had been preinjected with Xenopus U6 genes and labeled with $\alpha-{ }^{32} \mathrm{P}$-labeled nucleoside triphosphates. The major, slowly migrating form of newly made U6 RNA was complexed with protein(s), since its mobility increased to that of free U6 RNA after treatment with proteinase K. Northern blot analysis showed that this newly made RNP comigrated with an endogenous U6 RNP that was not complexed with U4 snRNA (data not shown).

For a more detailed analysis of the U6 snRNP, we developed a system to reconstitute this U6 snRNP by using U6 RNA synthesized in vitro (T7U6 RNA) and proteins

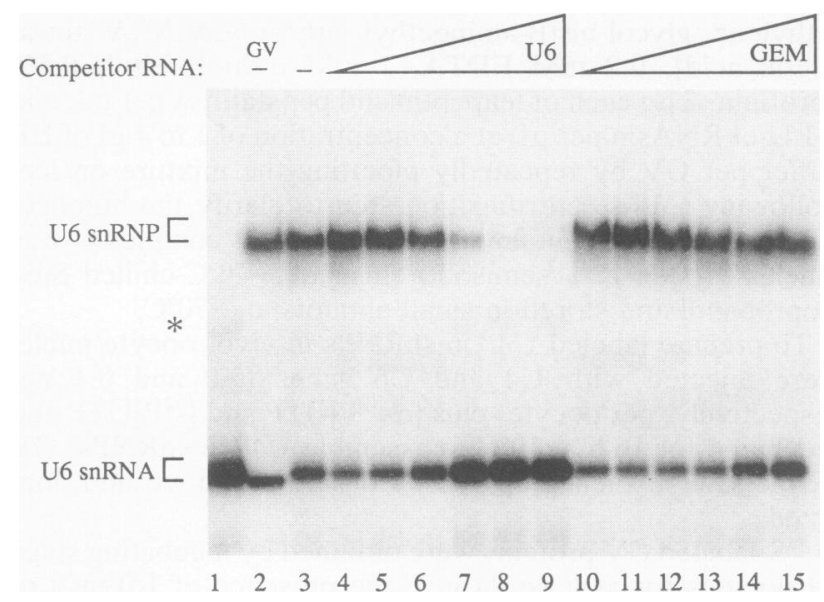

FIG. 1. Identification of a U6 snRNP. Native gel analysis of U6 snRNPs in GV extracts. ${ }^{32}$ P-labeled U6 RNAs synthesized either in isolated GVs preinjected with wild-type U6 genes (lane 2) or in vitro by transcription with T7 RNA polymerase (lanes 1 and 3 to 15) were mixed with $\mathrm{GV}$ extract ( $0.5 \mathrm{GV}$ equivalent per lane) prior to addition of unlabeled competitor RNA (wild-type T7U6 RNA and GEM RNA). Lanes 4 to 9 and 10 to 15 contained $0.1,0.5,1.0,2.5,5.0$, and $10.0 \mathrm{ng}$ (1- to 100 -fold molar excess) of competitor RNA, respectively. Lane 1 shows protein-free U6 RNA, and lanes 2 and 3 are extract samples lacking competitor RNA. The positions of proteinfree U6 RNA and the major U6 snRNP are indicated; the asterisk denotes a minor species of free U6 RNA.

present in the GV extract. The sequence of the T7U6 RNA is identical to that of $X$. laevis U6 RNA, except for two extra $G$ residues at the $5^{\prime}$ end. The reconstituted U6 snRNPs had the same electrophoretic mobility as the U6 snRNPs assembled in intact GVs (Fig. 1A, compare lanes 2 and 3). Incorporation of ${ }^{32} \mathrm{P}$-labeled T7U6 RNA into U6 snRNPs was strongly inhibited by unlabeled U6 RNA (lanes 4 to 9) but not by a similarly sized, unrelated RNA transcript of pGEM vector sequences (lanes 10 to 15). Escherichia coli tRNA also failed to compete for complex formation, even at concentrations as high as $5 \mathrm{mg} / \mathrm{ml}$ (data not shown). The demonstration that the nuclear U6 snRNP can be faithfully reconstituted from exogenously added U6 RNA indicates that specific complex formation is not obligatorily coupled to transcription.

To determine whether the association of U6 RNA and the protein(s) is readily reversible, competitor RNA was also added to preassembled U6 snRNPs. Labeled U6 RNA present in the preformed U6 snRNPs was displaced from the complexes by addition of competitor U6 RNA but not by addition of GEM RNA (data not shown). This displacement was observed regardless of whether the U6 snRNP was formed in vitro by using T7U6 RNA or within intact GVs that had been injected with U6 genes. These results indicate that proteins associate with U6 RNA in a specific but readily exchangeable manner.

A mutant version of U6 RNA ( $\Delta \mathrm{ss})$, lacking six nucleotides from within the single-stranded region adjacent to the 5 ' stem-loop structure (20), was also tested to determine whether the deleted region is required for U6 snRNP complex formation. This mutant U6 RNA assembled into complexes that have mobility and sensitivity similar to those of the two competitor RNAs as complexes that contain wildtype U6 RNA (data not shown). Thus, sequences that are required for both 5' capping and nuclear import of U6 RNA 


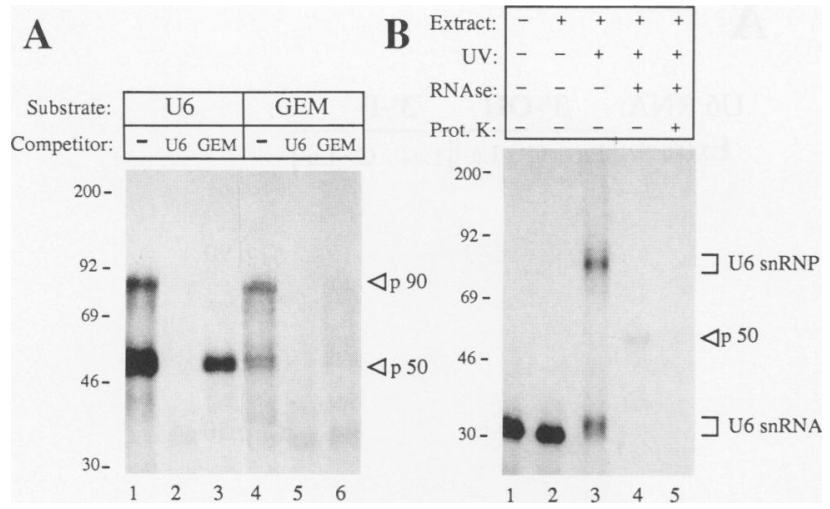

FIG. 2. Analysis of the UV cross-linked U6 snRNP. (A) UV light-induced RNA-protein cross-linking of the U6 snRNP. ${ }^{32} \mathrm{P}$ labeled T7U6 and GEM substrate RNAs were incubated with GV extracts $(0.25 \mathrm{GV}$ equivalent per reaction) in the absence (lanes 1 and 4) or presence of $50 \mathrm{ng}$ of unlabeled U6 RNA (lanes 2 and 5) or GEM RNA (lanes 3 and 6). The samples were irradiated with UV light, treated with RNases A and T1, and subjected to electrophoresis on SDS-containing $10 \%$ polyacrylamide gels. The major crosslinked protein species p50 and p90 are indicated on the right. (B) Complexity of the UV cross-linked U6 snRNPs. ${ }^{32}$ P-labeled T7U6 RNA was incubated in the absence (lane 1) or presence (lanes 2 to 5) of GV extract containing unlabeled GEM RNA (50 ng). Lane 2 shows a reaction that was not irradiated with UV light. The irradiated samples (lanes 3 to 5) were either untreated (lane 3), treated with RNases A and T1 (lane 4), or treated with the RNases plus proteinase (Prot.) $\mathbf{K}$ (lane 5). One-fifth of the total reaction sample was analyzed in lanes 1 to 3 . Electrophoresis was done as described for panel 2A; the major cross-linked RNP and proteins, as well as molecular weight protein standards $\left(10^{3}\right)$, are indicated.

$(20,43)$ are not necessary for assembly of the observed U6 snRNP.

Characterization of the U6 snRNP particle by UV lightinduced RNA-protein cross-linking. Proteins in two major size classes of about 50 (p50) and 90 (p90) kDa were identified as directly interacting with ${ }^{32} \mathrm{P}$-labeled U6 RNA by label transfer after UV cross-linking (Fig. 2A). p50 binds specifically to U6 RNA, whereas p90 (which often migrates as a doublet) binds nonspecifically to RNA in general. This was shown by comparison of the UV cross-linked products obtained by incubation of labeled T7U6 or GEM RNA in GV extracts in the absence or presence of unlabeled competitor RNAs. Although both RNAs labeled p50 and p90 in the absence of an added competitor, the level of p50 labeling was much lower when GEM rather than U6 RNA was used as the label source (Fig. 2A, compare lanes 1 and 4). Competitor U6 RNA prevented labeling of both protein species by either RNA (lanes 2 and 5); in contrast, the nonspecific competitor GEM RNA (lane 3) or tRNA (data not shown) prevented labeling of $\mathrm{p} 90$ but not $\mathrm{p} 50$ by radioactive U6 RNA.

UV cross-linked U6 snRNP, analyzed in the same denaturing gel system but without RNase treatment (Fig. 2B), migrated with a size of approximately $80 \mathrm{kDa}$ (lane 3), whereas free U6 RNA had the expected mobility of approximately $30 \mathrm{kDa}$ (lane 1 ). Detection of this $80-\mathrm{kDa}$ species was dependent on UV irradiation (lane 2). Treatment of the UV-irradiated sample with RNases resulted in appearance of the $50-\mathrm{kDa}$ labeled species and in degradation of the free RNA (lane 4); the protein nature of this $50-\mathrm{kDa}$ species was verified by further treatment with proteinase $\mathrm{K}$ (lane 5). Although the cross-linking of an additional small protein (which could have escaped detection by label transfer) cannot be strictly ruled out, these results establish that the major cross-linked U6 snRNP $(80 \mathrm{kDa})$ is likely formed by the binding of a single 50-kDa protein to a single U6 RNA (30 $\mathrm{kDa}$ ).

The U6 snRNP is an La RNP. The fact that U6 RNA is synthesized by RNA polymerase III and the correspondence in size between the UV cross-linked p50 and the nuclear antigen La (44) led us to examine whether the U6 RNP contained the La protein. When ${ }^{35} \mathrm{~S}$-labeled GV extracts were incubated with several different anti-La antibodies (Fig. 3A and data not shown), a single $50-\mathrm{kDa}$ protein that was not observed with control antibodies was precipitated (compare lanes 2 and 3). As shown in Fig. 3B, these anti-La antibodies, but not control antibodies (data not shown), also precipitated U6 snRNPs containing RNAs made in GVs (lanes 1 to 4 ) or added to GV extracts (lanes 5 and 6). The mutant U6 RNA ( $\Delta \mathrm{ss}$ ) lacking six nucleotides of the singlestranded region was also precipitated by the anti-La antibodies, indicating that the deleted region is not essential for $\mathrm{La}$ binding. The proportions of La-bound and unbound forms of U6 RNA were consistent with the fractions of U6 RNA observed to be free or protein bound during native gel electrophoresis (Fig. 1). Similar results were obtained by using several different human anti-La sera (listed in Materials and Methods); however, one serum (Ze) had high affinity for free La protein but not for U6 snRNPs (data not shown).

The anti-La antibodies selectively and quantitatively precipitated UV cross-linked p50 but not p90 (Fig. 3C, lane 4). Likewise, the antibodies precipitated cross-linked U6 snRNPs assembled in vivo (Fig. 3D); the appearance of free U6 RNA in the sample of lane 3 is likely due to incomplete cross-linking of La-bound U6 RNA. These results confirm that the labeled p50 is the La protein which binds specifically to U6 RNA; the competition experiments show that p90 is a nonspecific RNA-binding protein(s).

Defining the sequences in U6 snRNA important for La binding. Previous investigations have shown that the La protein binds preferentially to RNAs bearing oligouridylate with $\mathrm{OH}$ groups at their $3^{\prime}$ ends $(8,33,38,40,44)$. As shown in Fig. 4A, conversion of the $3^{\prime} \mathrm{OH}$ end group of U6 RNA to a $3^{\prime}$ phosphate destroyed the ability of U6 RNA to bind to and label the 50-kDa protein (compare lanes 1 and 4 or 2 and $5)$. Immunodepletion of the extracts confirmed that this protein was La (lanes 3 and 6). Direct contact between the 3' oligouridylate and the La protein was demonstrated by comparison of two-dimensional RNase T1 fingerprints of U6 snRNA that either had (La-bound) or had not (Free) been UV cross-linked to the $50-\mathrm{kDa}$ protein (Fig. 4B). The only oligonucleotides whose mobilities were changed by UV irradiation after incubation in extract were from the $3^{\prime}$ end of the RNA (arrowheads). The same results were obtained when this analysis was repeated by using U6 RNA labeled with both $\left[{ }^{32} \mathrm{P}\right] \mathrm{GTP}$ and $\left[{ }^{32} \mathrm{P}\right] \mathrm{UTP}$ and ensuring that oligonucleotides not labeled by $\left[{ }^{32} \mathrm{P}\right] \mathrm{UTP}$ were also monitored (data not shown). We conclude that $\mathrm{La}$ interacts with and cross-links to the $3^{\prime}$ terminus of full-length U6 RNA.

Association of La with endogenous U6 snRNA. Having demonstrated that the La protein binds specifically to newly made U6 snRNA, we asked whether it also binds preexisting, endogenous U6 RNA, either free or in U4/U6 snRNPs. Approximately 10 to $20 \%$ of the endogenous U6 RNA in $X$. laevis oocyte GVs terminate with a uridylate residue bearing a $2^{\prime}, 3^{\prime}$-cis diol, preceded by a variable number of uridylates, whereas most ( 80 to $90 \%$ ) of the U6 RNAs have $2^{\prime}, 3^{\prime}$-cyclic phosphate at the end of five uridy- 


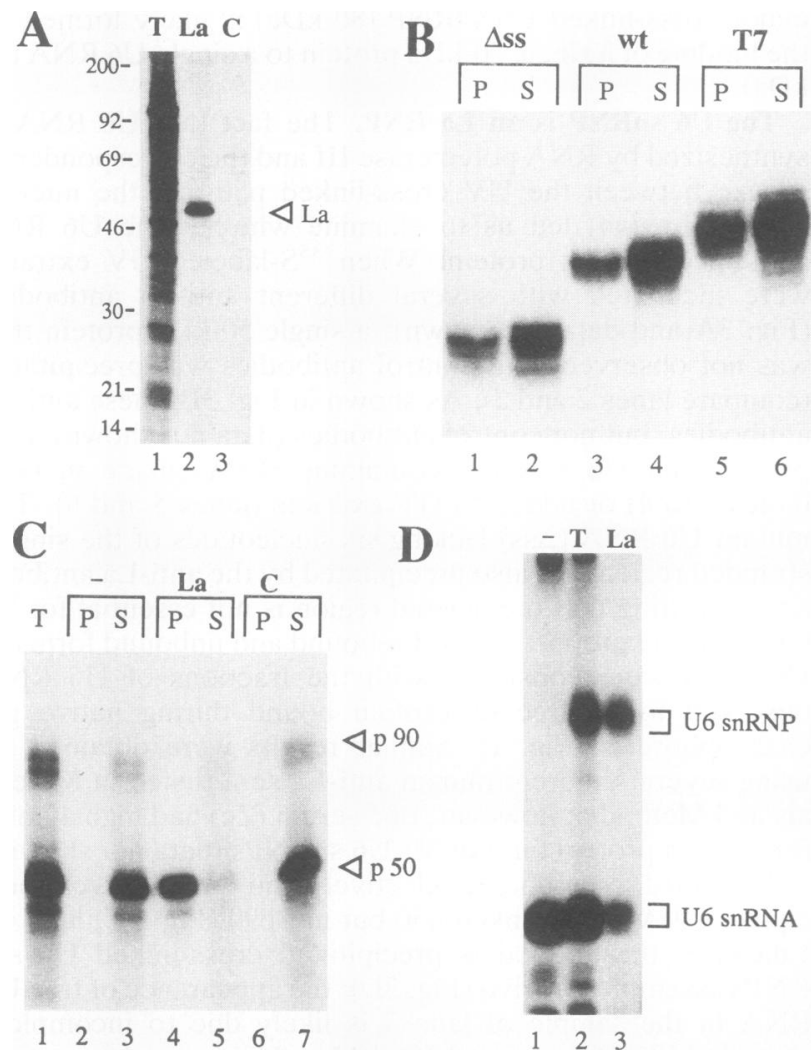

FIG. 3. La protein and U6 RNA in the U6 snRNP. (A) Immunoprecipitation of the La protein in Xenopus GV extracts. Four GV equivalents of ${ }^{35} \mathrm{~S}$-labeled extract was used for precipitations with anti-La antibodies (La, lane 2) or control normal human antibodies (C, lane 3). Lane 1 (T) contained the total GV proteins present in $1 / 20$ of a GV. The samples were resolved by electrophoresis on an SDS-containing $12.5 \%$ polyacrylamide gel, and the autoradiographic exposure of lanes 2 and 3 was 10 times longer than that of lane 1 . The numbers on the left are molecular weights in thousands. (B) Anti-La immunoprecipitation of GV extracts containing U6 RNA. RNAs were purified from both the precipitate $(P)$ and supernatant fraction (S) and analyzed by electrophoresis on a fully denaturing $7 \mathrm{M}$ urea-containing $8 \%$ polyacrylamide gel. ${ }^{32} \mathrm{P}$-labeled U6 RNAs were synthesized either in isolated GVs (lanes 1 to 4 ) or in vitro (lanes 5 and 6); $\Delta$ ss U6 RNA (lanes 1 and 2) lacks nucleotides 20 to 25 , which are located within the single-stranded region of U6 adjacent to the $5^{\prime}$ stem-loop structure (20). wt, wild type. (C) Immunoprecipitation by anti-La antibodies of proteins cross-linked to U6 snRNA. Reconstituted ${ }^{32}$ P-labeled T7U6 snRNPs were irradiated with UV light and treated with RNases $\mathrm{A}$ and $\mathrm{T} 1$, and the resultant ${ }^{32} \mathrm{P}$-labeled, cross-linked proteins were immunoprecipitated with anti-La antibodies ( $\mathrm{La}$, lanes 4 and 5 ) or with control normal human antibodies (C, lanes 6 and 7). A control immunoprecipitation was carried out in the absence of antibodies (-, lanes 2 and 3 ). The total sample ( $\mathrm{T}$, lane 1), precipitates (P), and supernatants (S) were separated by electrophoresis on an SDS-containing $10 \%$ polyacrylamide gel. (D) Anti-La precipitation of U6 snRNPs assembled in vivo. ${ }^{32} \mathrm{P}$-labeled U6 RNA was synthesized in isolated GVs preinjected with U6 genes. The GV extracts were UV irradiated but not RNase treated. The total GV extract sample (lane 2) and anti-La-precipitable extract sample (lane 3) are shown. Electrophoresis was done as described for panel 3C, and the positions of free RNA (lane 1) and cross-linked U6 snRNP are indicated. The appearance of free RNA in lane 3 is likely due to incomplete cross-linking of La-bound U6 RNA.
A

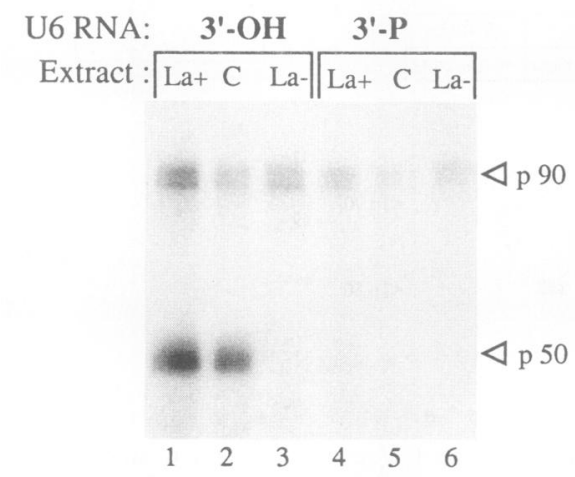

B

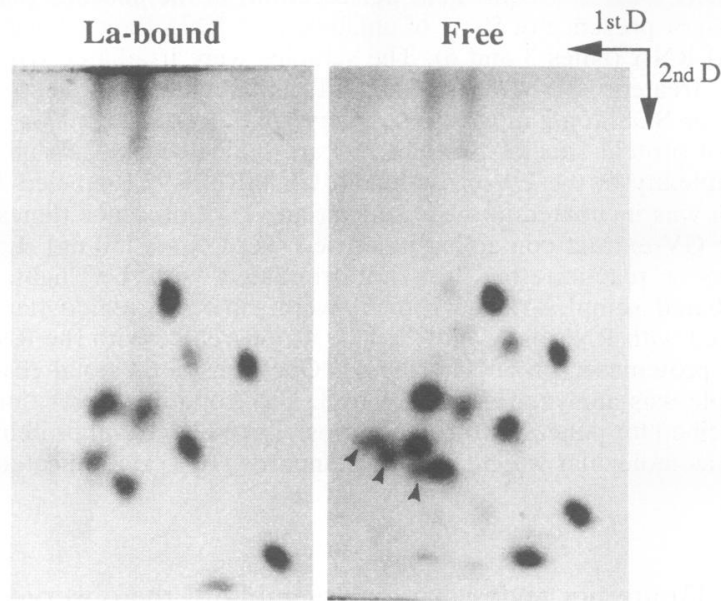

FIG. 4. Interaction of La with the $3^{\prime}$ terminus of U6 RNA. (A) Formation of U6 snRNPs with modified $3^{\prime}$ termini in untreated and La-depleted GV extracts. U6 snRNPs were reconstituted by using untreated $\left(\mathrm{La}^{+}\right)$, mock-depleted $(\mathrm{C})$, or La-depleted $\left(\mathrm{La}^{-}\right) \mathrm{GV}$ extracts and ${ }^{32} \mathrm{P}$-labeled T7U6 RNAs containing either 3' hydroxyl (lanes 1 to 3 ) or $3^{\prime}$ phosphate end groups (lanes 4 to 6). The UV cross-linked proteins p50 and p 90 were analyzed as described in the legend to Fig. 2A. (B) Mapping of the site in U6 RNA to which the La protein is crosslinked. Two-dimensional RNase T1 fingerprints of La-bound and free forms of $\left[{ }^{32} \mathrm{P}\right]$ UTP-labeled U6 RNA that were purified from an SDS-containing $10 \%$ polyacrylamide gel following UV irradiation of reconstituted T7U6 snRNPs (these RNA samples were purified from a preparative gel similar to that shown in Fig. 2B, lane 3 ). The arrowheads indicate the 3 '-terminal U6 oligonucleotides, which differ from each other by having three, four, and five terminal UMP residues $(30,31)$. The directions of the first and second dimensions are indicated. The low yields of two oligonucleotides (no. 15 and 20, according to the numbering system of reference 14) were unaffected by the presence or absence of added GV extract. Oligonucleotide 20 was found to be prone to overdigestion by RNase T1, and oligonucleotide 15 is prone to destruction or intramolecular cross-linking by UV irradiation.

lates $(30,32)$. Contrary to a previous report $(20)$, we found that a significant amount of the endogenous U6 RNA was precipitable by anti-La antibodies and hence was complexed with La protein (Fig. 5A, lane 4). However, the fastestmigrating form of U6 RNA $(>p)$ was not precipitable by the antibody, presumably because this form has a $2^{\prime}, 3^{\prime}$-cyclic phosphate terminus which prevents its association with La.

In contrast to the profile of U6 RNAs precipitated by 
A



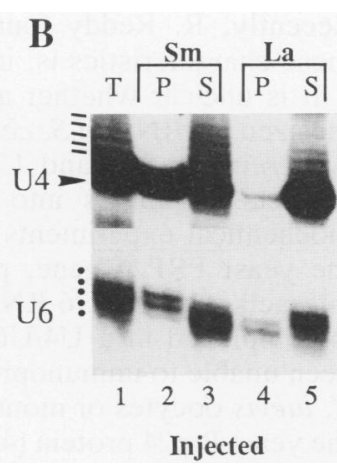

Injected

FIG. 5. Analysis of U6 RNA forms present in U6 snRNP and U4/U6 snRNP complexes. (A) Immunoprecipitation of endogenous U4 and U6 snRNAs. Northern blot analysis of antibody-selected endogenous U6 and U4 snRNAs from four oocyte GVs. The RNAs present in the nonprecipitated total sample ( $T$, lane 1$)$ and in the anti-Sm precipitate (lane 2) and supernatant (lane 3) or in the anti-La precipitate (lane 4) are shown. The fastest-migrating form of U6 RNA, containing $2^{\prime}, 3^{\prime}$-cyclic phosphate $3^{\prime}$-end groups, is indicated by the arrowhead, and the more slowly migrating forms of U6 RNA (containing 3' hydroxyl end groups and differing from each other with regard to the number of terminal uridylate residues) are denoted by dots. (B) Immunoprecipitation of U4 and U6 snRNAs present in GV extracts containing newly made U4/U6 snRNPs. Oocytes injected with $\mathrm{U} 4$ and U6 genes plus $\left[\alpha-{ }^{32} \mathrm{P}\right] \mathrm{GTP}$ and $\left[\alpha-{ }^{32} \mathrm{P}\right] \mathrm{UTP}$ were incubated for $16 \mathrm{~h}$ at $19^{\circ} \mathrm{C}$ to allow for in vivo assembly of ${ }^{32} \mathrm{P}$-labeled U4/U6 snRNPs. GV extracts were immunoprecipitated by using anti-Sm and anti-La antibodies, and RNAs from both the precipitate $(\mathrm{P})$ and supernatant $(\mathrm{S})$ fractions were analyzed by electrophoresis on a fully denaturing $7 \mathrm{M}$ urea-8\% polyacrylamide gel. The different-mobility forms of U6 RNA (dots) and precursor (slashes) and mature (arrowhead) forms of U4 RNA (30) are indicated.

anti-La antibody, the RNAs precipitated by anti-Sm antibodies, i.e., those U6 RNAs in U4/U6 complexes $(4,21)$, represent a rapidly migrating subset of U6 RNAs (Fig. 5A, lanes 2 and 3). Although the major anti-Sm-precipitable form of U6 RNA has a 2', 3'-cyclic phosphate (32), a small but significant amount of other forms of U6 RNA, with intermediate mobilities, is precipitable; molecules in this class have $3^{\prime} \mathrm{OH}$ end groups and stretches of uridylate 5 to 8 residues long (32). Despite having an La-binding site at their $3^{\prime}$ ends, these intermediate forms of U4/U6 snRNPs appear not to be bound to the La protein, since anti-La antibody did not coprecipitate detectable amounts of U4 RNA (lane 4). Thus, either the La protein is excluded from U4/U6 snRNPs or its reactive epitopes are masked in such complexes. The longer, more slowly migrating U6 RNAs apparent in lane 3 either are not incorporated into U4/U6 complexes or are rapidly shortened to the intermediate length upon complex formation.

A substantial fraction of the endogenous U6 snRNAs of $X$. laevis oocytes is not complexed with the La protein (lane 4) and is not precipitated by levels of anti-Sm antibody that are sufficient for precipitation of all of the U4 snRNPs in the extract (lanes 2 and 3 ). We found that about 20 to $25 \%$ of the total U6 RNA of oocytes was in U4/U6 snRNPs (a level significantly higher than that reported by others [20]) and about $10 \%$ was precipitable by anti-La antibodies. Still, about 65 to $70 \%$ of the U6 RNA cannot be accounted for by either complex. This population consists primarily of molecules with $2^{\prime}, 3^{\prime}$-cyclic phosphate termini that do not bind to the La protein.

Distribution of newly made U6 RNA between La and U4/U6

complexes. The nonrandom distribution of endogenous U6 RNAs between complexes that are precipitable by anti-Sm or anti-La antibodies led us to ask whether a similar selection is evident for newly made U4/U6 complexes and U6 snRNPs. To form labeled U4/U6 snRNPs, a mixture of U4 and U6 genes (plus [ $\left.{ }^{32} \mathrm{P}\right] \mathrm{UTP}$ and $\left[{ }^{32} \mathrm{P}\right] \mathrm{GTP}$ ) was coinjected into $X$. laevis oocyte nuclei; as described elsewhere (32), such newly made U6 RNAs, including those in U4/U6 complexes, all terminate with $3^{\prime}$ hydroxyl groups rather than a cyclic phosphate. Incorporation of some of the newly made U6 RNA into U4/U6 was demonstrated both by the precipitability of U6 RNA by anti-Sm antibody (Fig. 5B) and by cosedimentation of U4 and U6 RNAs during glycerol gradient centrifugation (data not shown).

The newly made U6 RNAs precipitable by anti-Sm antibody have the same mobility as the endogenous RNAs with intermediate mobility seen in Fig. 5A, lane 2. Surprisingly, the U6 RNAs precipitable by anti-La antibody migrated faster, rather than slower, than the U6 RNAs in U4/U6 complexes. Perhaps posttranscriptional 3 '-end elongation is a requirement for incorporation of U6 RNA into U4/U6 snRNPs, since only longer U6 RNA forms became precipitable by anti-Sm antibodies (Fig. 5B, lane 2, and fingerprint analysis [data not shown]). The shorter U6 RNA forms were, however, long enough to be bound to $\mathrm{La}$ (lane 4). Thus, La binding alone is not sufficient for incorporation of U6 RNA into U4/U6 snRNP. Furthermore, incorporation of U6 RNA into U4/U6 complexes may require that U6 RNA first be lengthened at its $3^{\prime}$ end.

The newly made U6 RNAs in U4/U6 snRNPs appear not to be bound to La. Anti-La antibody did precipitate a small amount of U4-sized RNA (Fig. 5B, lane 4), but this material is very unlikely to be U4 RNA in a U4/U6 snRNP, since it was also precipitable from extracts prepared from GVs injected with U4 genes in the absence of U6 genes (data not shown). Thus, it is likely that the anti-La-precipitable U4sized transcript is either U4 RNA that binds nonspecifically to La or an unrelated RNA polymerase III transcript encoded by the injected U4 plasmid. We conclude that $\mathrm{La}$ is not associated with the newly synthesized U6 RNA in U4/U6 snRNPs. To determine whether U6 RNAs in U4/U6 complexes could still bind $\mathrm{La}$, the anti-Sm-precipitable U6 RNAs were reisolated and tested for the ability to assemble into anti-La-precipitable complexes in GV extracts. All forms of the RNA were precipitable by this antibody (data not shown), demonstrating that no irreversible alteration of the U6 RNA had occurred to prevent its association with the La protein.

\section{DISCUSSION}

We have shown that U6 RNA assembles into snRNPs both in vivo and in vitro. In contrast to other spliceosomal snRNPs, we detected U6 snRNA associated with only a single protein, the nuclear antigen La. Identification of the 50-kDa U6-binding protein as the La protein was established by immunoprecipitation of U6 snRNA by using several anti-La antibodies, by immunodepletion of extracts, and by UV light-induced RNA-protein cross-linking.

These results demonstrate the importance of the uridylaterich, 3' hydroxyl terminus of U6 RNA in the La-U6 RNA interaction. La binds selectively to U6 RNAs with $2^{\prime}, 3^{\prime}-\mathrm{OH}$ groups at their oligouridylate termini but not to RNAs with $3^{\prime}$ phosphates or $2^{\prime}, 3^{\prime}$-cyclic phosphates (Fig. 4 and 5). This observation is consistent with an earlier published report on the reduced binding of biochemically purified La to tRNA 
substrates altered at their $3^{\prime}$ ends (44). Furthermore, by UV cross-linking and RNase T1 fingerprinting, we have directly identified the major site of cross-linking between the La protein and wild-type U6 RNA as the 3 '-terminal oligonucleotide which contains an oligouridylate tract (Fig. 4B). These observations explain the selective precipitation by anti-La antibodies of a subset of U6 RNAs from mammalian cells (41)

At its $3^{\prime}$ end, much of the newly synthesized U6 RNA initially contains five or fewer uridylic acid residues (32), consistent with the notion that the presence of five deoxyadenylates in the template strand of the $X$. laevis U6 gene (24) serves to terminate U6 transcription (16). Posttranscriptional addition of several more uridylate residues $(22,31,37)$ may be needed for recruitment of U6 transcripts into antiSm-precipitable U4/U6 snRNP complexes, as the shortest U6 RNAs are not present in newly formed U4/U6 complexes (Fig. 5B, lanes 2 and 4 and reference 32). However, U6 RNAs with very long $3^{\prime}$ extensions (more than eight uridylate residues) are not present in U4/U6 snRNPs (Fig. 5A, lanes 2 and 3); this suggests that these longer U6 RNA forms either are not assembled into U4/U6 complexes or undergo shortening prior to or soon after their incorporation into the bi-snRNP complex.

The major binding site of $\mathrm{La}$ is a $3^{\prime}$-terminal uridylate tract shared by RNA polymerase III transcripts $(8,33,38,40,44)$. In contrast to most other RNA polymerase III products, which lose their La-binding sites through removal of $3^{\prime}$ terminal uridylates $(8,33,40)$, U6 RNA loses its ability to bind to the La protein either by modification of the $3^{\prime} \mathrm{OH}$ or by formation of a complex with the U4 snRNP. The mechanism of conversion of the $2^{\prime}, 3^{\prime}$-cis diol to $2^{\prime}, 3^{\prime}>p$ is unclear, and we have been unable to achieve this alteration in an experimental system. However, U4/U6 snRNP formation can be promoted by coinjection of U4 and U6 snRNA genes into oocyte GVs (Fig. 5B and reference 47).

The lack of precipitation by anti-La antibody of U4 RNA from endogenous or newly made U4/U6 complexes suggests that the La protein is somehow excluded from the bi-snRNP particle. We cannot rule out the possibility that $\mathrm{La}$ is present in U4/U6 complexes but is no longer recognized by anti-La antibodies. However, the absence of $\mathrm{La}$ in biochemically purified U4/U6 snRNPs $(2,27)$ supports the conclusion that the protein is absent from U4/U6 snRNPs.

Our results showing that $\mathrm{La}$ binds to newly synthesized U6 RNA in $X$. laevis oocytes differs from conclusions of a previous study (20). Differences in the anti-La sera used could account for this discrepancy. Our results, obtained with a variety of anti-La sera, confirm that certain antibodies are species specific or have the ability to recognize free $\mathrm{La}$ protein but not La complexed with RNA (data not shown). Furthermore, many monoclonal and polyclonal anti-La antibodies raised against recombinant human La protein do not efficiently precipitate the $X$. laevis La protein $(9,10 \mathrm{a}$, and data not shown). Thus, the $50-\mathrm{kDa}$ protein that copurifies with U6 RNA from $X$. laevis oocytes (20) might be La.

Although La binds preferentially to RNAs at their oligouridylate-rich $3^{\prime}$ ends, it does bind other sites with lower affinity $(15,36)$. This property of La may explain our finding that La can bind a truncated form of U6 RNA lacking 48 nucleotides from its $3^{\prime}$ end (data not shown). Such an association, while less stable than the binding of full-length RNA, could explain the recent report of two proteins from HeLa and trypanosomal extracts (55 and $50 \mathrm{kDa}$, respectively) that bind a $5^{\prime}$ fragment of U6 RNA (17). Neither of these proteins was tested for the possibility that it is La.
Recently, R. Reddy found that a HeLa cell protein with these characteristics is, in fact, La (36a).

It is unclear whether a La-like protein binds newly synthesized U6 RNA of $S$. cerevisiae. A La-like protein exists in $S$. cerevisiae (6), and U6 RNA synthesized in yeast cell extracts assembles into a small RNP (7a). Genetic and biochemical experiments show that the protein product of the yeast PRP24 gene, predicted to be a $51-\mathrm{kDa}$ protein, interacts with the U6 RNA prior to, but not after, the RNA is complexed in a U4/U6 snRNP (42). However, we have been unable to immunoprecipitate U6 RNA from extracts of $X$. laevis oocytes or mouse cells by using antibodies against the yeast Prp24 protein (45a). Further studies are required to determine whether a yeast homolog of the vertebrate La protein exists and whether Prp24 is such a protein.

There is no compelling evidence that a protein other than La forms a stable complex with full-length vertebrate U6 RNA. Presumably, enzymes that modify the 5' and 3 ' ends or internal nucleotides bind to U6 RNA, at least transiently. Micrococcal nuclease treatment of GV extracts to release putative U6 RNA-binding proteins from endogenous U6 RNPs did not result in binding of proteins, other than $\mathrm{La}$, to newly made U6 RNA (data not shown). The lack of complex formation in La-depleted GV extracts (Fig. 4A and data not shown) indicates that if stable binding of U6 RNA to other proteins occurs, it either is $\mathrm{La}$ dependent or requires conditions other than those used here.

As summarized in Fig. 6, about $10 \%$ of the total U6 RNAs of $X$. laevis oocyte GVs are precipitable by anti-La antibody (Fig. 5A). This fraction is the same as that observed for La-precipitable U6 RNA in mammalian cells (41) and is also consistent with the levels of U6 RNAs in these two cell types that do not have $2^{\prime}, 3^{\prime}>$ p ends (Fig. 5A and reference 30). We detected about $25 \%$ of the U6 RNA of frog GVs in anti-Smprecipitable U4/U6 snRNP complexes. Although most of the U6 RNA in such complexes contains $2^{\prime}, 3^{\prime}$-cyclic phosphate end groups, a minor fraction of endogenous U6 RNA containing $3^{\prime}$ hydroxyl groups is also present within bi-snRNP complexes. Furthermore, newly made U6 RNAs exclusively containing $3^{\prime}$ hydroxyl termini become incorporated into U4/U6 complexes (Fig. 5B), raising the possibility that the $3^{\prime}$ end of U6 RNA receives a $2^{\prime}, 3^{\prime}$-cyclic phosphate end group only after assembly of U4/U6 complexes. Perhaps this conversion occurs as a consequence of the participation of U6 RNA in pre-mRNA splicing. A large fraction of the endogenous U6 RNAs, both in frog GVs (Fig. 5A) and in mammalian cells (30), is not precipitable by either anti-La or anti-Sm antibodies, indicating that the RNA is not complexed with either La protein or U4 snRNPs. This fraction of U6 RNA contains the $2^{\prime}, 3^{\prime}$-cyclic phosphate end group, but it is unclear whether this RNA is naked or complexed with proteins that are yet to be identified.

The association of La with U6 RNA could have several consequences in the overall metabolism of this RNA. It is likely that bound La would protect the newly made U6 RNA against exonucleolytic degradation. Furthermore, La binding might facilitate the maturation of U6 RNA by either retaining the RNA in the nucleus or localizing it to sites within the nucleus where the RNA is processed. La binding might also affect $3^{\prime}$-end maturation or incorporation of newly made U6 RNA into U4/U6 snRNP complexes by modulating the interaction of U6 RNA with various enzymes.

The generation of a $2^{\prime}, 3^{\prime}$-cyclic phosphate U6 RNA terminal group may ensure that the La protein does not bind to U6 RNA in spliceosomes. Such an interaction could be inhibitory to U6 RNA function if the La protein interfered 

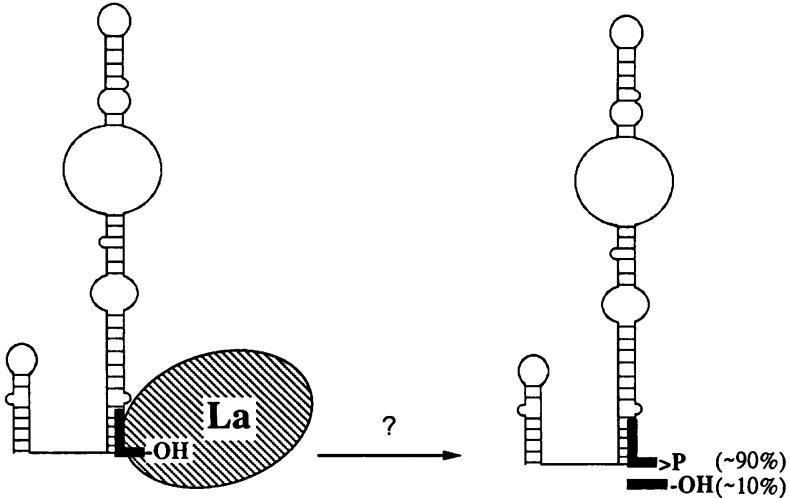

Complexed with La $(\sim 10 \%)$

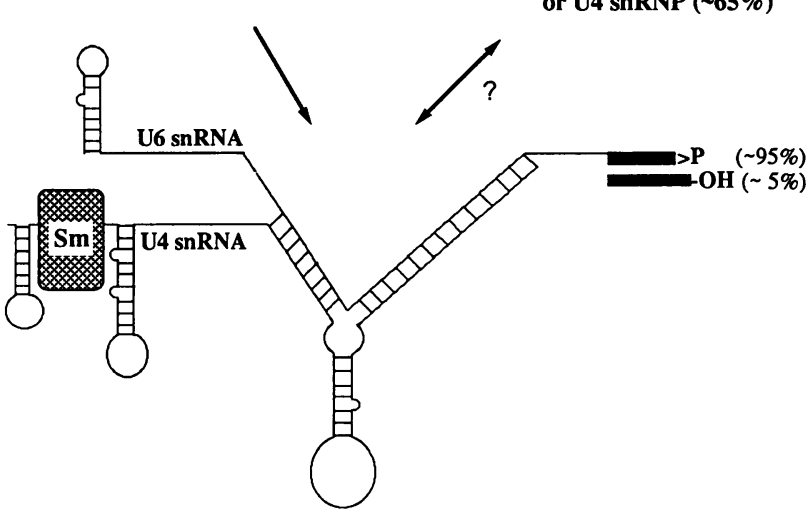

U4/U6 SnRNP ( 25\%)

FIG. 6. Relative distribution of U6 RNA forms in $X$. laevis oocyte nuclei. The La protein binds to newly synthesized U6 RNAs at their $3^{\prime}$ uridylate tract (solid black region) when they contain $3^{\prime}$ hydroxyl $(-\mathrm{OH})$ but not when they contain $2^{\prime}, 3^{\prime}$-cyclic phosphate $(>\mathrm{P})$ termini. La no longer binds to U6 RNAs that become incorporated into anti-Sm-precipitable U4/U6 snRNPs. The U4/U6 complex is drawn in accordance with the structure proposed by Brow and Guthrie (5). The relative percentages of the different forms of U6 RNA are indicated.

with interactions between U6 RNA and other spliceosomal components, such as U2 snRNA, which base pairs with U6 snRNA close to the La-binding site $(12,48)$.

\section{ACKNOWLEDGMENTS}

We thank R. Reddy, E. Chan, E. Tan, J. Steitz, D. Kenan, J. Keene, K. Shannon, and C. Guthrie for kindly providing antibodies used in this study and A. Krol and I. Mattaj for supplying wild-type and mutant U6 genes, respectively. Also, we thank L. Kahan for use of some laboratory equipment, L. Kahan and M. A. D. Brow for technical advice, D. Brow for helpful discussions, and D. Brow and D. Fortner for critically reading the manuscript.

This work was supported by NIH grant GM30220 to J.E.D. and E.L. and NIH postdoctoral fellowship GM14704 to M.P.T.

\section{REFERENCES}

1. Barrell, B. G. 1971. Fractionation and sequence analysis of radioactive nucleotides. Prog. Nucleic Acid Res. 2:751-779.

2. Behrens, S.-E., and R. Lührmann. 1991. Immunoaffinity purification of a [U4/U6.U5] tri-snRNP from human cells. Genes Dev. 5:1439-1452.

3. Black, D., and A. L. Pinto. 1989. U5 small nuclear ribonucleoprotein: RNA structure analysis and ATP-dependent interaction with U4/U6. Mol. Cell. Biol. 9:3350-3359.
4. Bringmann, P., B. Appel, J. Rinke, R. Reuter, H. Theissen, and R. Lührmann. 1984. Evidence for the existence of snRNAs U4 and U6 in a single ribonucleoprotein complex and for their association by intramolecular base pairing. EMBO J. 3:13571363.

5. Brow, D., and C. Guthrie. 1988. Spliceosomal RNA U6 is remarkably conserved from yeast to mammals. Nature (London) 334:213-217.

6. Brow, D. A. 1987. In vitro transcripts of a yeast variant $5 \mathrm{~S}$ rRNA gene exhibit alterations in 3 '-end processing and protein binding. J. Biol. Chem. 262:13959-13965.

7. Brow, D. A., and E. P. Geiduschek. 1987. Modulation of yeast 5 S rRNA synthesis in vitro by ribosomal protein YL3. J. Biol. Chem. 262:13953-13958.

7a.Buermeyer, A., D. Fortner, and D. Brow. Personal communication.

8. Chambers, J. C., M. G. Kurilla, and J. D. Keene. 1983. Association between the 7S RNA and the lupus La protein varies among cell types. J. Biol. Chem. 258:11438-11441.

9. Chan, E. K. L., and E. M. Tan. 1987. Human autoantibodyreactive epitopes of SS-B/La are highly conserved in comparison with epitopes recognized by murine monoclonal antibodies. J. Exp. Med. 166:1627-1640.

10. Cheng, S., and J. Abelson. 1987. Spliceosome assembly in yeast. Genes Dev. 1:1014-1027.

10a.Clarkson, S. Personal communication.

11. Dahlberg, J. E., and E. Lund. 1988. The genes and transcription of the major small nuclear RNAs, p. 38-70. In M. L. Birnstiel (ed.), Structure and function of major and minor small nuclear ribonucleoprotein particles. Springer-Verlag, Heidelberg.

12. Datta, B., and A. M. Weiner. 1991. Genetic evidence for base pairing between U2 and U6 snRNA in mammalian mRNA splicing. Nature (London) 352:821-824.

13. Dreyfuss, G., S. A. Adam, and Y. D. Choi. 1984. Physical change in cytoplasmic messenger ribonucleoproteins in cells treated with inhibitors of mRNA transcription. Mol. Cell. Biol. 4:415423.

14. Epstein, P., R. Reddy, D. Henning, and H. Busch. 1980. The nucleotide sequence of nuclear U6 (4.7 S) RNA. J. Biol. Chem. 18:8901-8906.

15. Francoeur, A. M., and M. B. Mathews. 1982. Interaction between VA RNA and the lupus antigen La; formation of a ribonucleoprotein in vitro. Proc. Natl. Acad. Sci. USA 79:67726776.

16. Geiduschek, E. P., and G. P. Tocchini-Valentini. 1988. Transcription by RNA polymerase III. Annu. Rev. Biochem. 57: 873-914.

17. Gröning, K., Z. Palfi, S. Gupta, M. Cross, T. Wolff, and A. Bindereif. 1991. A new U6 small nuclear ribonucleoproteinspecific protein conserved between cis- and trans-splicing systems. Mol. Cell. Biol. 11:2026-2034.

18. Gurdon, J. B., and M. P. Wickens. 1983. The use of Xenopus oocytes for the expression of cloned genes. Methods Enzymol. 101:370-386.

19. Guthrie, C., and B. Patterson. 1988. Spliceosomal snRNAs. Annu. Rev. Genet. 22:387-419.

20. Hamm, J., and I. Mattaj. 1989. An abundant U6 snRNP found in germ cells and embryos of Xenopus laevis. EMBO J. 13: $4179-4187$.

21. Hashimoto, C., and J. A. Steitz. 1984. U4 and U6 RNAs coexist in a single small nuclear ribonucleoprotein particle. Nucleic Acids Res. 12:3283-3293.

22. Hirai, H., D. I. Lee, S. Natori, and K. Sekimizu. 1988. Uridylation of U6 snRNA in a nuclear extract of Ehrlich ascites tumor cells. J. Biochem. 104:991-994.

23. Konarska, M. M., and P. A. Sharp. 1987. Interactions between small ribonucleoprotein particles in formation of spliceosomes. Cell 49:763-774.

24. Krol, A., P. Carbon, J. P. Ebel, and B. Appel. 1987. Xenopus tropicalis U6 snRNA genes transcribed by Pol III contain the upstream promoter elements used by Pol II dependent U snRNA genes. Nucleic Acids Res. 15:2463-2478.

25. Kunkel, G. R. 1991. RNA polymerase III transcription of genes 
that lack internal control regions. Biochim. Biophys. Acta 1088:1-9.

26. Lerner, E. A., M. R. Lerner, C. A. Janeway, Jr., and J. A. Steitz. 1981. Monoclonal antibodies to nucleic acid-containing cellular constituents: probes for molecular biology and autoimmune disease. Proc. Natl. Acad. Sci. USA 78:2737-2741.

27. Lührmann, R., B. Kastner, and M. Bach. 1990. Structure of spliceosomal snRNPs and their role in pre-mRNA splicing. Biochim. Biophys. Acta 1087:265-292.

28. Lund, E., and J. E. Dahlberg. 1987. Differential accumulation of U1 and U4 small nuclear RNAs during Xenopus development. Genes Dev. 1:39-46.

29. Lund, E., and J. E. Dahlberg. 1989. In vitro synthesis of vertebrate U1 snRNA. EMBO J. 8:287-292.

30. Lund, E., and J. E. Dahlberg. 1991. 2', 3'-Cyclic phosphates and nontemplated nucleotides at the 3' end of spliceosomal U6 small nuclear RNAs. Science 255:327-330.

31. Lund, E., and P. L. Paine. 1990. Nonaqueous isolation of transcriptionally active nuclei from Xenopus oocytes. Methods Enzymol. 181:36-43.

32. Lund, E., M. P. Terns, and J. E. Dahlberg. Unpublished data.

33. Mathews, M. B., and M. Francoeur. 1984. La antigen recognizes and binds to the $3^{\prime}$-oligouridylate tail of a small RNA. Mol. Cell. Biol. 4:1134-1140.

34. Melton, D., P. A. Krieg, M. R. Rebagliati, T. Maniatis, K. Zinn, and M. R. Green. 1984. Efficient in vitro synthesis of biologically active RNA and RNA hybridization probes from plasmids containing a bacterophage SP6 promoter. Nucleic Acids Res. 12:7035-7050.

35. Parry, H. D., D. Scherly, and I. Mattaj. 1989. 'Snurpogenesis': the transcription and assembly of U snRNP components. Trends Biochem. Sci. 14:15-19.

36. Pruijin, G. J. M., R. L. Slobbe, and W. J. van Venrooij. 1991. Analysis of protein-RNA interactions within Ro ribonucleoprotein complexes. Nucleic Acids Res. 19:5173-5180.

36a.Reddy, R. Personal communication.

37. Reddy, R., D. Henning, G. Das, M. Harless, and D. Wright. 1987. The capped U6 small nuclear RNA is transcribed by RNA polymerase III. J. Biol. Chem. 262:75-81.

38. Reddy, R., D. Henning, E. Tan, and H. Busch. 1983. Identification of a La protein binding site in a RNA polymerase III transcript (4.5I RNA). J. Biol. Chem. 258:8352-8356.

39. Reddy, R., and R. Singh. 1991. Synthesis of small nuclear RNAs. Prog. Mol. Subcell. Biol. 12:1-36.

40. Rinke, J., and J. A. Steitz. 1982. Precursor molecules of both human 5S ribosomal RNA and transfer RNAs are bound by a cellular protein reactive with anti-La lupus antibodies. Cell 29:149-159.

41. Rinke, J., and J. A. Steitz. 1985. Association of the lupus antigen La with a subset of U6 snRNA molecules. Nucleic Acids Res. 13:2617-2629.

42. Shannon, K., and C. Guthrie. 1991. Suppressors of a U4 snRNA mutation define a novel U6 snRNP protein with RNA-binding motifs. Genes Dev. 5:773-785.

43. Singh, R., S. Gupta, and R. Reddy. 1990. Capping of mammalian U6 small nuclear RNA is directed by a conserved stem-loop and AUAUAC sequence: conversion of a non-capped RNA into a capped RNA. Mol. Cell. Biol. 10:939-946.

44. Stefano, J. 1984. Purified lupus antigen La recognizes an oligouridylate stretch common to the 3 ' termini of RNA polymerase III transcripts. Cell 36:145-154.

45. Steitz, J. A., D. B. Black, V. Gerke, K. A. Parker, A. Kramer, D. Frendewey, and W. Keller. 1988. Functions of the abundant U-snRNPs, p. 115-154. In M. L. Birnstiel (ed.), Structure and function of major and minor small nuclear ribonucleoprotein particles. Springer-Verlag, Heidelberg.

45a.Terns, M. P. Unpublished data.

46. Terns, M. P., and S. T. Jacob. 1991. Potential role of poly(A) polymerase in the assembly of polyadenylation-specific RNP complexes. Nucleic Acids Res. 19:343-351.

47. Vankan, P., C. McGuigan, and I. W. Mattaj. 1990. Domains of U4 and U6 snRNAs required for snRNP assembly and splicing complementation in Xenopus oocytes. EMBO J. 9:3397-3404.

48. Wu, J., and J. L. Manley. 1991. Base pairing between U2 and U6 snRNAs is necessary for splicing of a mamalian pre-mRNA. Nature (London) 352:818-821. 